\title{
Actinide Packaging and Storage Facility (APSF)
}

\author{
A.D. Lavietes
}

\section{October 1, 1999}

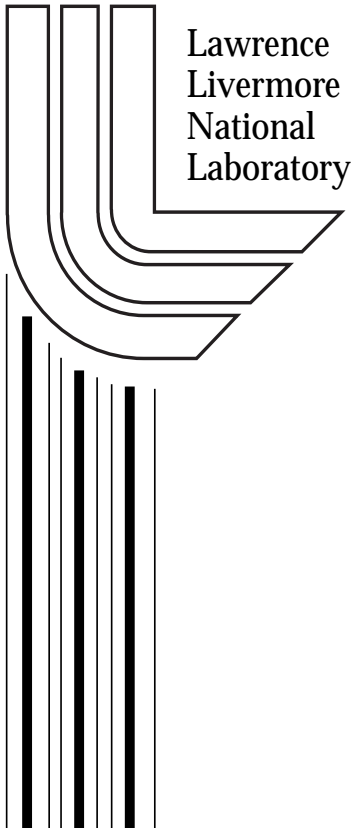




\section{DISCLAIMER}

This document was prepared as an account of work sponsored by an agency of the United States Government. Neither the United States Government nor the University of California nor any of their employees, makes any warranty, express or implied, or assumes any legal liability or responsibility for the accuracy, completeness, or usefulness of any information, apparatus, product, or process disclosed, or represents that its use would not infringe privately owned rights. Reference herein to any specific commercial product, process, or service by trade name, trademark, manufacturer, or otherwise, does not necessarily constitute or imply its endorsement, recommendation, or favoring by the United States Government or the University of California. The views and opinions of authors expressed herein do not necessarily state or reflect those of the United States Government or the University of California, and shall not be used for advertising or product endorsement purposes.

Work performed under the auspices of the U. S. Department of Energy by the University of California Lawrence Livermore National Laboratory under Contract W-7405-Eng-48.

This report has been reproduced directly from the best available copy.

Available to DOE and DOE contractors from the

Office of Scientific and Technical Information

P.O. Box 62, Oak Ridge, TN 37831

Prices available from (423) 576-8401

http://apollo.osti.gov/bridge/

Available to the public from the National Technical Information Service

U.S. Department of Commerce 5285 Port Royal Rd., Springfield, VA 22161 http://www.ntis.gov/

OR Lawrence Livermore National Laboratory Technical Information Department's Digital Library http://www.llnl.gov/tid/Library.html 


\section{Lawrence Livermore National Laboratory}

\section{Actinide Packaging and Storage Facility (APSF)}

Task A.229-Evaluate The Use Of Sensors On The AGVTo Verify Radiation From Pu, U, Or Np In Storage Containers, Including Remote Monitoring

\section{Final Report}

October 1, 1999 


\section{Purpose}

The Actinide Packaging and Storage Facility (APSF) was designed to provide long-term storage of radionuclides. Task A.229 defined the requirement for a small, low-power radiation detection capability. This detection system was to be deployed as a component of an autonomously guided vehicle (AGV) located within the storage vault of the facility and necessarily had to exhibit the qualities of low maintenance, long lifetime, and stable performance typically required of unattended monitoring systems. The detection system would interface directly with the on-board computer developed as part of the AGV under a separate task. The overall task for this system would be to provide isotopic identification of the material stored within this facility.

\section{Operational Parameters}

\section{Target Radiation Sources}

The radiation sources to be monitored were defined to be standard Department of Energy (DOE) 3013 canister filled with either uranium $(\mathrm{U})$, plutonium $(\mathrm{Pu})$, or neptunium $(\mathrm{Np})$. The amount of material present in any one canister was specified to be no more than $5 \mathrm{~kg}$, depending on the form (oxide or metal). It was determined that a canister would not contain a mixture of these materials. It was also understood that there could be several thousand canisters located within the APSF vault, arranged in an automated inventory system, with the potential for little or no shielding between canisters.

\section{System Description}

The radiation detection system was designed as three components;

Radiation detector

- $\quad$ EG\&G ORTEC Model 297 CZT Probe. This detector is a high-performance cadmium zinc telluride (CZT) based radiation detector that includes all necessary integrated electronics in a small, low-power unit.

Multichannel analyzer (MCA) - EG\&G ORTEC MicroNOMAD. This MCA was designed specifically to support the model 297 CZT detector probe and exhibits the electrical and mechanical qualities of low power and light weight required for this application.

Spectral analysis software - The software necessary to provide isotopic identification would be developed at Lawrence Livermore National Laboratory (LLNL) and be limited to the three isotopes of $\mathrm{U}, \mathrm{Pu}$, and NP. It is anticipated that this software would be based on existing isotopic identification codes developed at LLNL and would be referred to as CZTID.

It was determined that commercial products would be used where possible to provide ease of maintenance and reduced development costs. This methodology facilitated the selection of the ORTEC detector and CZT components and allowed the focus of the project to be the significant data acquisition and analysis issues. 
System Limitations

The main concerns for proper operation of this system were the large number of significant sources in close proximity and determination of the minimum required spectral acquisition time necessary for consistent and reliable results. Clearly, if the needs of the facility operations dictate complete periodic inventory assaying coupled with an anticipated inventory of several thousand units, the data acquisition system must be optimized to allow for rapid sampling. The speed at which the system will operate will be highly dependent on the requirements of the analysis code. The target for the spectral acquisition was initially and optimistically determined to be 5 minutes per sample.

Complicating the spectral acquisition issue is the anticipation of a large number of large sources in close proximity to the unit being measured. A detector collimator and shield will need to be developed to minimize these effects without significantly altering the data acquisition process.

It should be noted that testing this system with respect to these issues will provide significant challenges, specifically it may be unlikely that an actual measurement operation can be conducted that closely matches the anticipated environment, so true system performance may not be accurately evaluated until deployment. In lieu of this, tests will be conducted at the highest level achievable to provide confidence that the deployment scenario will be satisfied.

\section{Data Acquisition}

Data acquisition will be initiated by the receipt of a predetermined command from the AGV host computer. The detection system operational software will respond by beginning a spectral acquisition of the target source. It is assumed at this point that the target 3013 canister has been pre-selected with the detector positioned appropriately by the AGV. The detector is to be within $5 \mathrm{~cm}$ of the outer surface of the target canister. At the completion of the acquisition process, the spectrum is stored on the AGV computer with an appropriate file name reflecting a unique identity for tracking the measurement. When requested, the spectrum file is transferred to a separate facility for analysis.

\section{Data Analysis}

Separate isotopic analysis software has been developed for determining the identification of the material stored in the target 3013 canister. The code is designed to analyze the acquired spectrum for the unique signature of $\mathrm{U}, \mathrm{Pu}$, or $\mathrm{Np}$ by identifying specific energy lines in subject energy spectrum.

\section{Project Status}

\section{Hardware}

- $\quad$ A CZT-based detector probe (model 297) was purchased from EG\&G ORTEC that includes a $5 \times 5 \times 5 \mathrm{~mm}$ CZT detector supplied by eV Products. The detector was tested upon arrival and detector module was found to be inoperable. The failure mechanism appeared to be high-voltage breakdown on the crystal, a common failure. An existing detector at LLNL was used in place of the defective unit. 
- $\quad$ A PC-based ISA bus MCA card (EG\&G ORTEC MicroACE) was specified and procured, though was found to be inappropriate for this application. This MCA was to be replaced with an EG\&G ORTEC MicroNOMAD MCA specifically designed to support the $\mathrm{CZT}$ detector probe, though the project was suspended prior to the purchase.

- A custom collimator was designed and fabricated (Figure 1) to provide shielding from nearby sources during spectral acquisition. The collimator was fabricated from tantalum for optimized attenuation and shaped to allow viewing of the entire 3013 target canister diameter from a $5 \mathrm{~cm}$ distance.

\section{Software}

- CZTID, the analysis code designed for the isotopic identification task, has been initially tested in laboratory tests with energy spectra acquired for 30 minute periods.

- Operational and interface software has not been developed.

\section{Pending Tasks}

- Optimize the isotopic identification code and minimize the data acquisition process time.

- Design user interface for the analysis software.

- Design the AGV interface code for controlling the data acquisition process.

- Purchase an EG\&G ORTEC MicroNOMAD MCA.

- Deliver the system to Savannah River Site, demonstrate performance and train site personnel in system operation.

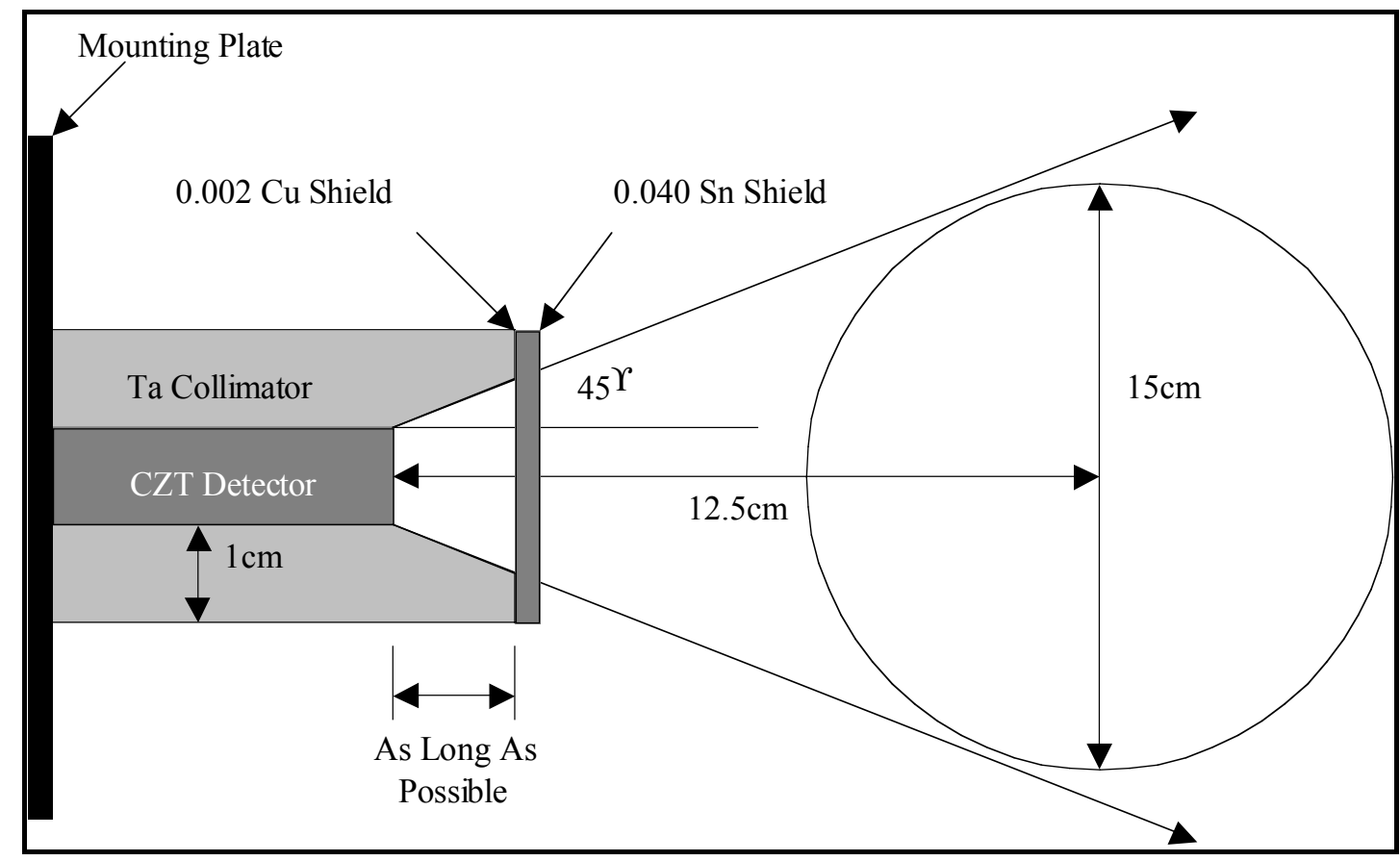

Figure 1 Collimator Design Drawing 


\section{Financial Status}

\begin{tabular}{|l|l|l|}
\hline Total Funding & $\$ 115 \mathrm{~K}$ \\
\hline Expenditures & & \\
\hline Funds Remaining & & \\
\hline
\end{tabular}

